\title{
LA ADAPTACIÓN DEL CÓDIGO DE PROCEDIMIENTO CIVIL VENEZOLANO AL PARADIGMA DEL NUEVO CONSTITUCIONALISMO LATINOAMERICANO: UNA REFORMA NECESARIA
}

\author{
Adaptation of the of the Venezuelan civil procedure code to new Latin \\ American constitutionalism paradigm: a necessary reform
}

\section{Albert NOGUERA FERNÁNDEZ}

Sumario:

I. Introducción: nueva Constitución y viejos códigos. II. La doble adecuación de la legislación a los nuevos paradigmas constitucionales. III. La adaptación del rol de los jueces en el proceso civil al nuevo constitucionalismo. IV. La democratización de la justicia y el proceso: una justicia adaptada al nuevo constitucionalismo. V. Conclusión. VI. Fuentes.

Resumen: La Constitución venezolana de 1999, ubicada conjuntamente con las Constituciones de Bolivia y Ecuador dentro de lo que se ha llamado el nuevo constitucionalismo latinoamericano, supuso la implementación en el país de un nuevo modelo constitucional. Quince años después de su entrada en vigor todavía hay leyes que no ha sido adaptadas al nuevo modelo, una de ellas es el Código de Procedimiento Civil. Actualmente, y con la intención de solventar este desajuste, se está tramitando en la Asamblea Nacional una reforma del Código que se espera sea aprobada antes de terminar el año 2015. El presente trabajo lleva a cabo un análisis de cuales son aquellos elementos que permiten adaptar esta norma de enjuiciameinto civil al paradigma del nuevo constitucionalismo latinoamericano y un estudio de algunos de los limites y potencialidades que ofrece el nuevo Código de Procedimiento Civil.

Palabras clave: Venezuela, nuevo constitucionalismo latinoamericano, Código deprocedimiento Civil.

Abstract: The Venezuelan Constitution of 1999, co-located with the constitutions of Bolivia and Ecuador in what has been called the new Latin American constitutionalism, involved the implementation in the country of a new constitutional model. Fifteen years after its entry into force there are still laws that has not been adapted to the new model, one is the Code of Civil Procedure.

Currently, with the aim of solving this mismatch, National Assembly is reforming the code which is expected to be approved before the end of 2015. This paper conducts an analysis of those elements which are used to adapt this rule of civil procedure to the paradigm of the new Latin American constitutionalism and a study of some of the limits and possibilities offered by the new Code.

Key words: Venezuela, new Latin American constitutionalism, Code of Civil Procedure.

\footnotetext{
${ }^{1}$ Profesor (titular acreditado) de Derecho Constitucional en la Universitat de València.
} 


\section{INTRODUCCIÓN: NUEVA CONSTITUCIÓN Y VIEJOS CÓDIGOS}

El 15 de diciembre de 1999 los venezolanos aprobaron en referéndum su actual Constitución, la cual se enmarca, conjuntamente con las constituciones ecuatoriana de 2008 y boliviana de 2009, en el interior de un nuevo modelo constitucional que algunos han llamado el neoconstitucionalismo latinoamericano ${ }^{2}$ y cuyos orígenes se han ubicado en la Asamblea Constituyente y Constitución colombiana de $1991 .^{3}$

Quince años después de la aprobación de la Constitución todavía hay en el país leyes que no han sido adaptadas al nuevo paradigma constitucional, una de ellas es el Código de Procedimiento Civil de 18 de septiembre de 1990.

Con el objetivo de solventar este desajuste, el diputado Elvis Amoroso (PSUV- Aragua), presidente de la Comisión de Política Interior, presentó en 2014 a la Asamblea Nacional un proyecto de reforma del Código elaborada a iniciativa del Tribunal Supremo de Justicia (TSJ). El 25 de noviembre de 2014 la Asamblea aprobó en primera discusión la reforma y se espera que antes de terminar el 2015 la reforma sea aprobada en lo particular.

El presente trabajo analiza las principales características del nuevo constitucionalismo latinoamericano para a partir de él ver cuáles son aquellos elementos que debería tener la nueva norma procesal civil para encajar mejor con el nuevo paradigma constitucional. Asimismo, se hace un estudio del proyecto de reforma del Código presentado a la Asamblea Nacional exponiendo sus potencialidades y sus límites.

\section{LA DOBLE ADECUACIÓN DE LA LEGISLACIÓN A LOS NUEVOS PARADIGMAS CONSTITUCIONALES}

Para poder hablar de un nuevo paradigma constitucional deben darse, a mi entender, dos elementos:

Uno es que un nuevo paradigma constitucional debe introducir o expresarse en desarrollos teóricos novedosos y nuevas constituciones escritas, conformadores, ambos, de un nuevo marco jurídico-constitucional de referencia.

Y, dos, es que este nuevo marco jurídico-constitucional sólo creará un paradigma cuando genere además un nuevo sistema de relaciones sociales, nuevas realidades culturales, sociales, económicas, políticas, económicas, jurisprudenciales, etc. Esto es, cuando genere nuevas "situaciones reales constitucionales".

Podemos hablar, por tanto, de nuevo paradigma constitucional cuando se produce una coincidencia en el tiempo entre: a) nuevos desarrollos teóricos en el ámbito constitucional; b) nuevas constituciones escritas; $y, c)$ nuevas situaciones reales constitucionales.

La mera transformación de la cotidianidad real o de la realidad constitucional sin que se haya producido un cambio en la Constitución escrita ni en sus fundamentos teóricos da lugar a lo que Laband, ${ }^{4}$ Jellinek ${ }^{5}$ o Shü Dau-Lin ${ }^{6}$ llamaron mutaciones constitucionales, esto

\footnotetext{
${ }^{2}$ R. VICIANO Y R. MARTÍNEZ, "Fundamentos teóricos y prácticos del nuevo constitucionalismo latinoamericano", Gaceta Constitucional, no. 48, Tribunal Constitucional, Lima, 2011, pp. 307-328.

3 Sobre ello, vid. A. NOGUERA y M. CRIADO, "La Constitución colombiana de 1991como punto de inicio del nuevo constitucionalismo en América Latina”, Estudios Socio-jurídicos, Universidad del Rosario, No. 13(1), Bogotá. 2001, pp. 15-49.

${ }^{4}$ M. LABAND, "Die geschichtliche Entwicklung der Reichsverfassung", en Jahrbuch des öffentlichen Rechts (JöR), Tomo I, 1907.

5 G. JELLINEK, Reforma y mutación de la Constitución, Centro de Estudios Constitucionales, Madrid, 1991.

${ }^{6}$ H. DAU-LIN, Mutación de la Constitución, IVAP, Bilbao, 1998.
} 
es una incongruencia entre realidad y normas, pero no a nuevos paradigmas constitucionales. O, a la inversa, nuevas escuelas de pensamiento o teorías constitucionales sin que ello se plasme en textos jurídicos escritos ni realidades concretas como pasó en Europa con el surgimiento, durante las décadas de los noventa, de las teorías neoconstitucionalistas ${ }^{7}$ pero sin que ellas dieran lugar a reformas de las constituciones escritas, tampoco genera nuevos paradigmas constitucionales.

En consecuencia, sólo podemos hablar, a mi entender, de nuevo paradigma constitucional cuando se dé una coincidencia histórico-concreta entre desarrollos teóricos novedosos, nuevas constituciones escritas y nuevas situaciones reales constitucionales.

De acuerdo con esta definición de paradigma constitucional, podemos decir que durante las últimas décadas hemos asistido en América Latina a la conformación de un nuevo para-

\footnotetext{
7 El origen de la llamada corriente neoconstitucionalista suele apuntarse hacia finales de la década de los noventa del siglo XX, cuando se publicaron los primeros trabajos de Susana Pozzolo y del grupo de filósofos del derecho de la Universidad de Génova que han desempeñado su labor en torno a la figura de Paolo Comanducci. El esfuerzo tenía por objetivo encontrar un denominador común en la doctrina sobre cuál es la función de la Constitución en el ordenamiento jurídico y el papel que juegan sus contenidos, para lo que bebieron de las más diversas fuentes tanto del mundo anglosajón (R. Dworkin, Freedom's Law: The Moral Reading of the American Constitutiom, Oxford UP, Oxford, 1996) como latinoamericano (C.S. Nino, The Constitution of Deliberative Democracy, Yale UP, New Haven-Londres, 1996). Y aquí tenemos la primera gran característica del neoconstitucionalismo: como fruto del pensamiento analítico, en un principio ha consistido en un análisis teórico sobre el valor jurídico de la Constitución y su influencia y jerarquía sobre el resto del ordenamiento jurídico, poniendo el énfasis en el papel y aplicación de los principios constitucionales. Aunque ha prescindido de elementos empíricos de comprobación, ha manifestado su voluntad de transcender hacia una nueva forma de aplicación del derecho. Supone, por ello, todo un esfuerzo de imaginación colectiva y análisis teórico que se inicia en la búsqueda de criterios específicos de interpretación de la Constitución respecto a la interpretación del resto del ordenamiento jurídico, y deriva hacia el papel de la Constitución y su aplicación en lo que suele denominarse Estado constitucional. ¿Cuáles serían aquellos elementos que configuran el núcleo del neoconstitucionalismo? Según S. Pozzolo ("Neoconstitucionalismo y especicidad de la interpretación constitucional. Doxa. Cuadernos de Filosofía del Derecho, 21(2), 1998, pp. 340-342), se trataría de cuatro formulaciones: 1) Principios vs. normas. Haciendo referencia velada al clásico debate de los años sesenta y setenta entre Hart y Dworkin, que se quiso entender como una crítica a los fundamentos del iuspositivismo, Pozzolo pone énfasis en la distinción entre principios y reglas ("normas") en el ordenamiento jurídico, y en el papel destacado que los principios deben representar en la función de interpretación y argumentación jurídica por parte de los jueces; 2) Ponderación vs. subsunción. Los principios contarían con un peculiar método interpretativo/aplicativo, porque no cabe su aplicación de acuerdo con los métodos de subsunción de las normas, sino que necesitan de la ponderación o balanceo cuya técnica consiste en detectar los principios aplicables al caso concreto, sopesar los principios localizados para poder ponerlos en relación jerárquica axiológica, y aplicar el principio que prevalece en un caso concreto con base en el juicio de valor particular formulado por el juez; 3) Constitución vs. independencia del legislador; esto es, la subordinación de la ley y del resto del ordenamiento jurídico al texto constitucional, lo que implicaría la materialización o sustancialización de la Constitución; una función semejante a la que previamente había desarrollado el derecho natural; 4) Libertad de los jueces vs. libertad del legislador. Se trata de defender la interpretación creativa de la jurisprudencia, imprescindible desde el momento que el juez abandona el método de la subsunción ante la presencia de los principios, y debe aplicar la Constitución frente a la ley convirtiéndose en un instrumento básico para la sustancialización de la misma (Sobre ello, vid. R. Viciano y R. Martinez, "La Constitución democrática, entre el neoconstitucionalismo y el nuevo constitucionalismo", El Otro derecho, No. 48, Bogotá, 2013, pp. 63-84).
} 
digma constitucional denominado por algunos como nuevo constitucionalismo latinoamericano. ${ }^{8}$

El surgimiento, creación y desarrollo teórico de este nuevo constitucionalismo bebe de distintas fuentes: de la preocupación por la supremacía constitucional característica del neoconstitucionalismo ya citado; de la tradición americana derivada de los convenants, que partiendo de una separación radical entre Poder constituyente soberano y poder constituido no soberano requiere la participación directa de la ciudadanía en los procesos decisorios ${ }^{9}$; de los teóricos de la plurinacionalidad; ${ }^{10} \mathrm{o}$ de las teorías del garantismo de autores como Ferrajoli, ${ }^{11}$ C. Courtis o V. Abramovich; ${ }^{12}$ etc.

El conjunto de estas fuentes o desarrollos teóricos tuvieron acogida y fueron de especial importancia en los procesos constituyentes que, desde la década de los noventa, se dieron en algunos países de la zona andina de América Latina y se plasmaron en las nuevas constituciones escritas de Colombia (1991), Venezuela (1999), Ecuador (1998 y 2008) y Bolivia (2009), así como en las nuevas situaciones reales constitucionales surgidas a partir de ellas en varios de estos países.

Esta coincidencia en el tiempo entre: a) nuevas teorías; b) nuevas constituciones escritas; $y, c)$ nuevas realidades; ha terminado conformando lo que podemos llamar un nuevo paradigma constitucional del que forma parte, entre otras, la Constitución venezolana de 1999.

Teniendo clara esta definición de paradigma constitucional como encaje entre teoría, Constitución escrita y nuevas realidades, podemos decir que la adecuación de la legislación vigente en los diversos sectores del ordenamiento jurídico de un país, también de la norma procesal civil, al nuevo paradigma exige un doble reto.

\subsection{LA ADECUACIÓN “POR ARRIBA"}

Por un lado, exige la necesidad de adaptar estas normas "por arriba", esto es adaptarlas a las nuevas concepciones teórico-doctrinales del nuevo constitucionalismo y a la propia constitución escrita. Como hemos señalado, la teoría neoconstitucionalista conforma una fuente importante del nuevo constitucionalismo latinoamericano, algunos de los rasgos propios de este paradigma plasmados en las nuevas constituciones son:

La percepción de la Constitución no sólo como un conjunto de disposiciones normativas que tienen supremacía respecto a las otras, sino que ésta aparece ahora cargada de nuevos principios y valores intrínsecos que deben impregnar toda la vida pública. La Constitución contiene principios materiales y sustantivos que condicionan la actuación del Estado por medio de la ordenación de ciertos fines y objetivos de justicia; La igual jerarquía e indivisi-

\footnotetext{
${ }^{8}$ R. VICIANO y R. MARTÍNEZ, "Fundamentos teóricos y prácticos del nuevo constitucionalismo latinoamericano".

${ }^{9}$ Sobre ello, vid. P. de VEGA, La reforma constitucional y la problemática del Poder Constituyente, Tecnos, Madrid, 1985, pp. 38-41.

${ }^{10}$ Véase L. TAPIA, Una reflexión sobre la idea de un Estado plurinacional, Enlace, La Paz, 20o8; L. Tapia, La condición multisocietal; multiculturalidad, pluralismo y modernidad, Muela del diablo/CLACSO, La Paz, 2002; O. Vega, Errancias. Aperturas para el buen vivir, Muela del Diablo/CLACSO, La Paz, 2010; O. Vega, "Estado plurinacional", en Constitución política del Estado. Anotada, concordada y comentada, Centro de Estudios Constitucionales, Universidad Católica Boliviana San Pablo, La Paz, 2013; R. Prada, Horizontes del cambio: Estado Plurinacional y socialismo comunitario, en I. Errejón y A. Serrano (coord.), Ahora es cuando, carajo! Del asalto a la transformación del Estado en Bolivia, El viejo topo, Madrid, 2011, pp. 145-168.

${ }^{11}$ L. FERRAJOLI, Derecho y razón. Teoría del garantismo penal, Trotta, Madrid, 1995.

${ }^{12}$ V. ABRAMOVICH y C. COURTIS, Los derechos sociales como derechos exigibles, Trotta, Madrid, 2002. 
bilidad de todos los derechos que pasan a ser definidos por P. Häberle como "magnitudes" (Grösen), los derechos ya no tendrían un contenido absoluto fijo sino que definen su contenido en función de las interrelaciones concretas con el resto de derechos; ${ }^{13} \mathrm{El}$ garantismo, desarrollado ampliamente por L. Ferrajoli; ${ }^{14} \mathrm{O}$, la redefinición de las prácticas jurisprudenciales, sustituyendo lo que G. Zagrevelsky llama un "constitucionalismo de reglas" basado en el imperio de la ley, por un "constitucionalismo de principios" basado en la aplicación directa de la Constitución. ${ }^{15}$ Los jueces deben aprender a realizar su función bajo parámetros interpretativos nuevos y más complejos. Entran ahora en juego las técnicas interpretativas propias de los principios constitucionales, la ponderación, la proporcionalidad, la razonabilidad, la maximización de los efectos normativos de los derechos, el efecto de irradiación, la proyección horizontal de los derechos a través de la Drittwirkung, etc. Además, los jueces se las tienen que ver con la dificultad de trabajar con valores que están constitucionalizados y que requieren una tarea hermenéutica que sea capaz de aplicarlos a los casos concretos de forma justificada y razonada, dotándolos de esa manera de contenido normativo concreto.

Por tanto, adaptar el código procesal civil a los nuevos paradigmas constitucionales exige, por un lado, adaptarlo "por arriba", a la teoría neoconstitucionalista y a las nuevas constituciones escritas.

\subsection{LA ADECUACIÓN “POR ABAJO”}

Pero por otro lado, existe también la necesidad de adoptar estas normas "por abajo", esto es a lo que hemos llamado la "situación constitucional real". Los viejos Códigos Procesales Civiles ya no sólo no encajan con los nuevos desarrollos teóricos y textos constitucionales escritos, sino que tampoco encajan con las nuevas realidades sociales, políticas, culturales, etc. desarrolladas en algunos de los países latinoamericanos durante los últimos años.

Podemos poner un ejemplo de nuevas situaciones constitucionales reales consolidadas en estos países durante los últimos años y que contradicen la concepción civilista clásica sobre la que se construyeron los viejos códigos procesales civiles. Este es, la sustitución de una concepción de las relaciones sociales basada en la idea civilista clásica del "hombre contra hombre" por otra basada en la del "hombre más hombre", lo que implica cambios en los sujetos o partes litigantes de referencia. Detengámonos en ello.

Hay que partir de la idea de que del Derecho Civil y sus formas procesales tienen su origen en el s. XIX en el marco de una concepción atomista de las relaciones sociales donde los individuos se concebían como un conjunto de piezas autónomas y aisladas con interés propio e individual que actuaban como meros intercambiadores en el mercado. En este contexto, cualquier delimitación del contenido de su interés se resolvía en el marco de un juicio de

\footnotetext{
${ }^{13}$ P. HÄBERLE, (1998), Libertad, igualdad, fraternidad. 1789 como historia, actualidad y futuro del Estado Constitucional, Trotta, Madrid, 1998, p. 104.

${ }^{14}$ L. FERRAJOLI, Derecho y razón. Teoría del garantismo penal.

${ }^{15}$ G. ZAGREVELSKY, El derecho dúctil, Trotta, Madrid, 2011.
} 
"hombre contra hombre" donde ambos se encontraban en una supuesta situación de igualdad jurídica plena.

Por esta razón, los mecanismos procesales tipo creados dentro de los paradigmas del derecho de propiedad del s. XIX fueron elaborados pensando en juicios bilaterales entre dos partes individuales en situación de igualdad como parte o sujeto litigante de referencia.

Sin embargo, a medida que se va dando una mayor politización de la sociedad, y no cabe duda que la Constitución venezolana al des-identificar la política de las instituciones del Estado y re-identificarla con la acción colectiva ${ }^{16}$ ha dado lugar a una mayor politización social, los sectores populares más vulnerables social y económicamente van adquiriendo conciencia de la que la manera de satisfacer sus intereses personales no es la vía individual del "hombre contra hombre" pues no estarán nunca en una situación de plena igualdad jurídica real con los poderosos, sino que es optar por su conformación en sujetos colectivos, por la vía de la organización comunitaria o del "hombre más hombre", que es la que puede situarlos colectivamente en condiciones de igualdad para enfrentar jurídicamente con viabilidad y posibilidades de éxito a los sectores más poderosos.

Ello hace que, cada vez más, las partes, también en los procesos civiles, ya no sólo sean sujetos individuales, juicios entre individuos, sino también sujetos colectivos (asambleas de vecinos, comunidades de pescadores, comisiones de barrio, grupos de consumidores, etc.), lo que supone, como señalábamos antes, novedades y cambios en las partes o sujetos litigantes de referencia previstos en el Derecho Procesal Civil tradicional. ${ }^{17}$

En resumen, la adecuación del Código Procesal Civil venezolano a los nuevos paradigmas constitucionales, exige una no fácil y necesaria doble acomodación o adaptación: por un lado, reformas que permitan adaptar la norma "por arriba", esto es a las novedades surgidas en la teoría constitucional y a la Constitución escrita; y, por otro lado, adaptarla "por abajo", esto es a la "situación real constitucional" del país. Países como Bolivia, otro de los máximos exponentes del neoconstitucionalismo latinoamericano, ya han llevado a cabo la adaptación de su Código Procesal Civil a la nueva Constitución boliviana de 2009 mediante la aprobación en diciembre de 2013 de un nuevo código (Ley 439) que y entró en vigor en agosto de 2014 y sustituye al anterior de 1976.

El planteamiento o estudio de cómo adecuar la norma procesal civil a estos dos ámbitos del nuevo constitucionalismo exige primero de todo y antes de entrar en discusiones micro o técnico-concretas especializadas de cómo configurar figuras, instituciones o momentos concretos del proceso (discusión que quien mejor pueden hacer son los procesalistas y los operadores jurídicos), enfocarse desde una perspectiva "macro", sistémica, de modelo de derecho procesal civil en general. Primero, hay que ver cuál es el modelo procesal civil tipo que se adecua a la filosofía y lógica del nuevo constitucionalismo. Ello es lo que intentaremos plantear a continuación. Con este objetivo nos centraremos en dos cuestiones aquí fundamentales: una es la relación entre técnica judicial, normas jurídicas, y partes del proceso o,

\footnotetext{
${ }^{16}$ Vid. A. Noguera, "Reflexiones a partir del análisis del presidencialismo en la Constitución venezolana: acción de gobierno y articulación Ejecutivo-ciudadanos". En F. Palacios y D. Velázquez (coord.). Estudios sobre la Constitución de la República Bolivariana de Venezuela. X Aniversario, Procuraduría General de la Republica, Caracas, 2009, pp. 315-328.

${ }^{17}$ Podríamos poner otros ejemplos. Otra forma de adecuación de la norma procesal civil a las nuevas realidades culturales, sociales, etc. es la introducción de notificación en forma electrónica, ya sea por e-mail o SMS, lo que permite además ahorrar mucho tiempo para notificaciones (Sobre ello, vid. N. Cabezudo, Del principio de inmediación, sus excepciones y los instrumentos electrónicos, Tirant lo Blanch, València, 2010, pp. 55 y ss.).
} 
dicho de otra manera, el papel o rol de los jueces en el proceso civil; y la otra, vinculada a la primera, es la cuestión de la democratización de la justicia y del proceso.

III. LA ADAPTACión DEL ROL DE LOS JUECES EN EL PROCESO CIVIL AL NUEVO CONSTITUCIONALISMO

\subsection{PRINCIPIOS Y FORMAS DEL PROCESO}

En los sistemas jurídicos comparados podemos identificar una serie de valores calificados como principios que vertebran todo proceso como fórmula de resolución de conflictos. Se trata de elementos tales como la dualidad de posiciones, los principios de audiencia y contradicción o la igualdad entre las partes. Se trata de elementos, todos ellos, que deben encontrarse presentes a fin de que el proceso pueda ser considerado como tal. Son aquellos valores que la doctrina especializada califica como "principios inherentes a la estructura del proceso" ${ }^{18}$ o "principios jurídicos naturales, ${ }^{19}$ comunes $^{20}$ y absolutos ${ }^{21 "}$ y que, sin duda, podemos considerar principios constitutivos del proceso.

Ahora bien, al lado de estos principios coexisten otras reglas cuya satisfacción no es esencial. Se trata de determinados criterios que pueden incidir en la actividad procesal o en la forma de los actos, como por ejemplo, el principio dispositivo y/o de oficialidad, el principio de aportación de parte, de investigación de oficio, de concentración de actos, etc. Todos estos elementos son contingentes y entra dentro de la oportunidad legislativa reconocerlos de una manera u otra, sin que esa circunstancia afecte a la existencia del proceso. Su eventual previsión o no será reflejo de uno u otro modelo concreto que la ideología política dominante en cada momento histórico-concreto quiera imponer.

Para diferenciar entre los elementos disponibles y no disponibles para el legislador, algunos autores usan la distinción entre "principios" y "formas" del proceso. Por tanto, en función de cómo el legislador configure estos elementos disponibles o formas del proceso, estaremos ante modelos procesales civiles distintos. Lo que haremos a continuación es ver los dos grandes modelos procesales tipo que existen, para, a continuación, ver cuál de estos dos modelos es el que encaja mejor con el nuevo paradigma constitucional del nuevo constitucionalismo latinoamericano.

\subsubsection{LOS MODELOS PROCESALES TIPO}

La decisión del juez en un proceso es siempre una decisión motivada, y aquí entiendo por "motivada" como un adjetivo que puede otorgarse únicamente a pensamientos o enunciados obtenidos de la experiencia sensible o la deducción. Lo motivado se asocia a la lógica.

\footnotetext{
${ }^{18}$ V. GIMENO Sendra, Introducción al Derecho Procesal, Madrid, 2003, pp. 263 y ss.

19 A. Oliva SANTOS, I. DIEZ-PICAZO GIMÉNEZ y J. VEGA, Derecho Procesal, Editorial universitaria Ramón Areses, Madrid, 2004, pp. 49 y ss.

${ }^{20}$ J. MONTERO AROCA, J.L. GÓMEZ COLOMER, A. MONTON y S. BARONA, Derecho Jurisdiccional I (parte general), Trinat lo Blanch, Valencia, 2007, pp. 331-342.

${ }^{21}$ J.M. ASENCIAO, Introducción al Derecho Procesal, Triant lo Blanch, Valencia, 2004, p. 196.
} 
Usamos el concepto "motivación” para referirnos a enunciados que pueden conectarse o deducirse de la experiencia.

Lo que diferencia a los dos grandes modelos procesales tipo es que la experiencia que lleva al juez a adoptar su decisión, es distinta: en el primero modelo, que llamaremos "modelo de justicia del procedimiento", es una experiencia donde el juez juega un papel pasivo. Mientras que en el segundo modelo, que llamaremos "modelo de justicia de la decisión", es una experiencia donde el juez juega un papel activo. La diferencia entre ambos modelos radica pues, en el papel y los poderes del juez, así como en su relación con las partes.

\section{A) LA JUSTICIA DEL PROCEDIMIENTO}

Este modelo reivindica la autonomía y la importancia del método en que consiste el proceso como mecanismo con vida propia a partir de cuyo desarrollo se desprende la verdad o solución de la controversia jurídica.

El propio desarrollo pausado, deliberativo y extendido del método del proceso permite que de él se vaya desprendiendo la solución del caso, con lo que lo único que realiza el juez al final del proceso en una "confirmación" del resultado dilucidado del propio proceso. La verdad fluye del método del procedimiento que llevan a cabo las partes o los peritos, no de una decisión final subjetiva del juez que juega aquí un rol de mero observador pasivo y ratificador de la verdad. En consecuencia, los protagonistas del esfuerzo de alegaciones y pruebas son aquí las partes y sus abogados, no los jueces, cuyo rol se limita a dirigir bien el proceso y ratificar mediante sentencia la verdad que fluye del método del procedimiento.

El método del procedimiento aparece como algo absoluto y autónomo de cuyo pausado desarrollo se desprende la verdad. Se asigna un status especial al procedimiento que no se puede limitar en pro de una mayor celeridad de la justicia. La realización y pleno cumplimiento pausado de todos los pasos del método procesal no pueden estar sometidos al cálculo de intereses sociales mayores.

Este modelo permitiría, afirman sus defensores, una resolución imparcial evitando el subjetivismo y el decisionismo judicial. De la correcta aplicación del método procesal legalmente establecido y reglamentado fluye la verdad final, independientemente del contexto, juez, lugar o momento donde se dé. Este es el modelo procesal tipo que inspira, por ejemplo, la vigente Ley 1/200o de Enjuiciamiento Civil española (LEC). Como se desprende del punto VI de su exposición de motivos, ${ }^{22}$ el papel del juez es totalmente pasivo. Si bien la LEC de 2000 introduce algunos elementos nuevos como la oralidad, la simplificación de procesos o la incorporación de las nuevas tecnologías en el proceso, es claramente continuista con el modelo procesal tipo de la LEC española de 1881. Es cierto que en artículos como el 429.1 LEC, ampliamente criticado por parte de la doctrina en España, se atribuye al juez el denominado "deber de aclaración y veracidad" que se manifiesta en la posibilidad del juez de

\footnotetext{
22 "De ordinario, el proceso civil responde a la iniciativa de quien considera necesaria una tutela judicial en función de sus derechos e intereses legítimos. Según el principio procesal citado, no se entiende razonable que al órgano jurisdiccional le incumba investigar y comprobar la veracidad de los hechos alegados como configuradores de un caso que pretendidamente requiere una respuesta de tutela conforme a Derecho. Tampoco se grava al tribunal con el deber y la responsabilidad de decidir qué tutela, de entre todas las posibles, puede ser la que corresponde al caso. Es a quien cree necesitar tutela a quien se atribuyen las cargas de pedirla, determinarla con suficiente precisión, alegar y probar los hechos y aducir los fundamentos jurídicos correspondientes a las pretensiones de aquella tutela. Justamente para afrontar esas cargas sin indefensión y con las debidas garantías, se impone a las partes, excepto en casos de singular simplicidad, estar asistidas de abogado”.
} 
solicitar de oficio a alguna de las partes la verificación de alguno de sus argumentos, pero ello no quita que exista en la LEC una hegemonía del dogma de que el protagonismo recae en las partes durante el proceso y no en la decisión del juez.

\section{B) LA JUSTICIA DE LA DECISIÓN}

Este modelo reivindica lo contrario, esto es un papel activo del juez y mayores poderes de éste en su relación con las partes. Las partes y los abogados pierden peso en favor del juez. Al demandante sólo se le pide narrar los hechos y formular genéricamente su pretensión, sin perjuicio de las pruebas que quiera aportar, mientras que será el juez a quien, conjuntamente con su función de dirección del proceso, le corresponderá además la tarea de llevar a cabo de oficio las averiguaciones pertinentes sobre los hechos narrados que considere relevantes, así como la búsqueda y selección de posibles normas aplicables al caso, para poder llegar a una decisión final.

En este modelo y como se ha afirmado irónicamente, "los jueces deben hacer justicia a pesar de los abogados". La resolución del caso recae sobre la actividad del juez y es fruto de su decisión. A diferencia del anterior modelo, este suele caracterizarse por una mayor celeridad procesal, fruto de la eliminación o reducción temporal de trámites no esenciales y de la articulación del proceso alrededor de los principios de inmediación del juez, de oralidad, o de concentración de los catos procesales en la audiencia.

Ejemplos de este modelo los encontramos en la tradición anglosajona del Common law donde la fuente principal de producción del derecho es el juez. En tal tradición, el procedimiento de producción y unificación del ordenamiento jurídico, el procedimiento judicial y la expresión normativa del sistema, tiene una naturaleza dual: en primer lugar la Constitución tiene un papel dirigente en tanto es considerada por sí misma una norma directamente aplicable y fuente de fuentes; $y$, en segundo término, la decisión judicial se convierte en la expresión normativa por antonomasia del ordenamiento.

\subsubsection{EL MODELO PROCESAL DEL NUEVO CONSTITUCIONALISMO LATINOAMERICANO}

Vistos los dos modelos tipo, ¿Cuál de ellos encaja mejor con el nuevo constitucionalismo latinoamericano? En cuál de ellos debería encuadrarse un Código de Procedimiento Civil adaptado al nuevo paradigma constitucional?

Parece claro que debería corresponder al segundo de los modelos descritos. Ello por dos razones principales:

Por un lado, porqué el modelo de justicia del procedimiento se basa en dos características abiertamente contradictorias con el paradigma constitucional del nuevo constitucionalismo.

Por otro lado, porqué así se desprende directamente de determinados artículos de la vigente Constitución venezolana de 2009. 


\section{A) LA CONTRADICCIÓN ENTRE JUSTICIA DEL PROCEDIMIENTO Y NEOCONSTITUCIONALISMO}

El modelo de justicia del procedimiento descrito presenta dos características abiertamente contradictorias con el nuevo constitucionalismo.

El primero lo encontramos en el hecho de que el procedimiento civil se vincula o se concibe como asociado a la concepción liberal-temprana o kantiana ${ }^{23}$ del Derecho como relación intersubjetiva.

La concepción libera-temprana de los s. XVIII a XIX, partía de una separación radical entre Estado y Sociedad, asignando a cada uno de estos ámbitos un estatuto jurídico diferente. Mientras el ámbito del Estado se regía por el derecho público; el ámbito de la Sociedad Civil, que era el mismo que el del mercado, ${ }^{24}$ se regía por el derecho privado.

En este segundo ámbito, el de la Sociedad Civil o mercado, regulado por el Código civil, era donde se establecían el complejo de relaciones entre seres "libres", "autónomos" e "iguales". Los únicos peligros que podían imaginarse para este espacio de libertad individual iusprivatista se derivaban de una posible intervención del Estado en las relaciones socioeconómicas que limitara tal libertad.

De ahí que en la concepción liberal-temprana, cualquier intervención del Estado en el ámbito de las relaciones intersubjetivas fuera visto como un ataque a la libertad. Esto valía tanto para las relaciones económicas, como para la resolución de conflictos jurídicos. La metáfora de la supuesta "mano invisible" que Adam Smith manifestaba en La riqueza de las naciones, serviría para expresar tanto una supuesta capacidad autoregulatoria del libre mercado, como una supuesta capacidad autoregulatoria de la Sociedad Civil para resolver sus conflictos mediante el acuerdo entre voluntades individuales con la mínima intervención del juez. De ahí que el proceso judicial en el ámbito civil se entienda a partir de la teoría kantiana de la relación intersubjetiva, según la cual el Derecho y el proceso judicial no es más que el conflicto, mediación y acuerdo entre dos voluntades individuales de conformidad con una ley general

\footnotetext{
${ }^{23}$ E. KANT, Metafísica dei costumi (Trad. Italiana), Utet, Torino, 1956, p. 407.

${ }^{24}$ El surgimiento de la idea de sociedad civil fue el resultado de la crisis, en el orden social, que se vivió en Europa a partir del siglo XVII, con el ciclo de revoluciones sociales iniciado por la revolución inglesa y continuado por la de las trece colonias y la francesa. Expresó el intento de resolver la crisis ideológica provocada por la quiebra de los paradigmas de la idea de orden. Los procesos sociales acaecidos en esta época condujeron al cuestionamiento de los modelos de orden social y de autoridad. Tradicionalmente, el fundamento del orden social se localizaba en alguna entidad externa al mundo social (Dios, el Rey o la tradición). Todo esto empezó a cuestionarse en el siglo XVII. La idea de sociedad civil surgió para proyectar una imagen ideal de cómo debía ser el funcionamiento de la sociedad, con la que se intentó teorizar la concepción del contrato como base de toda autoridad política y social. Esta idea de sociedad civil expresa la autonomización de lo social con respecto a lo político y lo estatal. En la sociedad civilmente organizada, "civilizada", los seres humanos son entendidos no como miembros de una comunidad, sino como individuos, sujetos autónomos (J.L. Acanda, Sociedad civil y hegemonía, Centro Juan Marinello, La Habana, 2002, pp. 136-137). Esta es la idea de sociedad civil que presenta Hegel en su Filosofía del Derecho. Para este autor, el concepto de Bürgerliche Gesellschaft (que podemos traducir como "sociedad civil burguesa") ya no designa a la societas civilis separada del "estado de naturaleza", sino a la imbricación mutua de los inidviduos en la prosecución de sus intereses privados. Es decir, su relación como burgeois (burgueses) y no como citoyen (ciudadanos). Hegel comprende la sociedad civil como una sociedad de individuos propietarios, iguales ante la ley, y poseedores de una libertad igual y general que interectúan en el espacio de mercado en beneficio propio, la aceptación de la tesis liberal de la propiedad como principio y fundamento de la libertad esté plenamente presente en Hegel. Para Hegel la sociedad civil burguesa es el "sistema de las necesidades" donde los hombres se relacionan entre sí como propietarios, por medio de sus relaciones con cosas [(Ver párrafo 40 de G.W.F. Hegel, Principios de la filosofía del derecho, Edhasa, Barcelona, 1987 (1821)].
} 
de libertad y donde el juez, representante del Estado, debe jugar un rol meramente pasivo limitándose a no intervenir y ratificar el resultado surgido de la intermediación entre partes. De lo contrario, estaría limitando las libertades individuales de las partes.

En consecuencia, el primero de los modelos, el de la justicia del procedimiento, tiene sus orígenes en modelos de sociedad donde se daba una separación radical entre Estado y Sociedad y donde el Estado no debía intervenir en las relaciones socio-económicas.

El nuevo constitucionalismo latinoamericano establece un modelo totalmente opuesto. Éste no se basa en una concepción del proceso entendido como mera relación inter-subjetiva interpartes sin la intervención del Estado, sino en un modelo garantista donde los jueces deben jugar un papel preponderante para la realización de los principios constitucionales de justicia. El carácter material o sustantivo y garantista del Estado aparece en el art. 2 de la Constitución venezolana que define al Estado como "social de derecho y de Justicia", expresión con la que se delimita su naturaleza y que coloca al Estado en una relación intrínseca con la noción de "social". Generalmente, la definición de un Estado como social ha implicado que el fin social impregna todo el articulado constitucional, el cual debe interpretarse en armonía con este fin. Y de hecho, de conformidad con esto, en el caso del texto constitucional venezolano, la naturaleza social del Estado se transversaliza a lo largo de todo el texto (arts. 112, 115, 178, etc.).

La Constitución introduce claramente una dimensión funcional en el fundamento de la tutela con el objeto de permitir una injerencia externa, esto es la llamada "funcionalización de las instituciones", como la función social de la propiedad, la función social de la empresa, etc. De todas estas disposiciones constitucionales se desprende una apelación constitucional directa a la intervención de los poderes públicos y de los organismos institucionales para la tutela del interés general y social, lo que obliga a los jueces a tener que adoptar un rol activo y enérgico en este sentido. Los jueces deben llevar a cabo lo que Dworkin denominó una "lectura moral de los casos"25, resolverlos a partir de una reconstrucción sistemática de la Constitución como un todo, a fin de aportar una interpretación coherente con los valores, fines y objetivos sociales del Estado.

El segundo rasgo que define al modelo de la justicia del procedimiento y que es abiertamente contradictorio con el nuevo constitucionalismo latinoamericano es que en el primero, el procedimiento civil se diseña y estructura desde el formalismo o positivismo jurídico y el imperio de la ley, lo que, como digo, es contrario al nuevo paradigma constitucional.

Llamo "formalismo jurídico" a aquella concepción del Derecho que tiene en una determinada lectura de Kelsen (aunque no la únic ${ }^{26}$ ) su máxima expresión y según la cual el Derecho no debe preocuparse por si las normas son justas o injustas, buenas o malas, por cuestiones morales, sino sólo por si son válidas, por si han sido producidas por el procedimiento correcto y por si se cumplen.

De acuerdo con ello, el proceso debe entenderse como una secuencia de actos técnicos legalmente establecidos y la función del juez debe consistir únicamente en asegurar, desde una posición pasiva de imparcialidad, que tales actos se cumplen correctamente para, al

\footnotetext{
${ }^{25}$ R. DWORKIN, Freedom's Law: The Moral Reading of the American Constitutiom.

${ }^{26}$ Sobre ello, vid. O. Correas, Kelsen y los marxistas, Coyoacán, México, 1994.
} 
final de los mismos, aplicar objetiva y técnicamente la ley en un ejercicio de técnica judicial mecánica.

En consecuencia, de esta concepción del proceso desde el formalismo jurídico y el imperio de la ley se deriva el primer modelo descrito, basado en una actitud pasiva y meramente técnica, no subjetivizada o ideologizada, como si esto fuera posible, del juez.

Digo que ello es contrario al nuevo constitucionalismo porqué este no se basa en el formalismo jurídico y le imperio de la ley sino en todo lo contrario, el nuevo constitucionalismo se construye desde el antiformalismo jurídico radical y desde la aplicación directa de la Constitución por encima de la ley. Una de las novedades del Estado Constitucional del s. XX, $\mathrm{y}$ en mayor grado el neoconstitucionalismo latinoamericano del s. XXI, es que crea lo que podríamos llamar una nueva "cultura jurídica de las fuentes del derecho", de la que deriva un inevitable cambio en el papel o función de los jueces. Digo que en el caso de las nuevas constituciones latinoamericanas ello se da en mayor grado que en el constitucionalismo del s. XX por las razones que desarrollo a continuación.

Con el paso del "Estado legislativo de derecho" del s. XIX al "Estado Constitucional de derecho" del s. XX se dan transformaciones importantes en el campo de las fuentes del derecho y en la propia naturaleza de la Constitución. La Constitución reemplaza a la ley en la cúspide del ordenamiento y del sistema de fuentes. Sin embargo, si bien este reemplazo de la ley por la Constitución como fuente principal de derecho opera indiscutiblemente para los poderes públicos, nos encontramos que, en la práctica, dentro del modelo de Estado Constitucional de derecho no todas las Constituciones reconocen la misma aplicabilidad directa de los distintos grupos de derechos. Ello hace que a pesar de haberse cambiado el modelo de Estado, en el ámbito de determinados derechos no se haya logrado una superación absoluta del viejo imperio de la ley ordinaria en la relación de los ciudadanos con la justicia ordinaria. Un ejemplo claro de ello es la cuestión de la justiciabilidad de los derechos sociales en España.

En materia de derechos sociales, la Constitución española (CE) de 1978 incorpora la mayoría de los derechos sociales clásicos, sin embargo parte de la idea de que éstos no son "derechos" sino que son otro tipo de normas legales, concretamente, principios o directrices para guiar las políticas sociales, ${ }^{27}$ precisamente por ello los ubica (a excepción del derecho

\footnotetext{
${ }^{27}$ Alguno de los principales argumentos que han utilizado aquellos que afirman que los derechos sociales no son "auténticos" derechos sino principios o directrices, es que no cumplen las características que cumplen los derechos civiles o políticos. La fórmula "X tiene un derecho a Y, en virtud de P", sólo es coherente, nos dicen, si se puede dar una explicación convincente: a) de quien es el titular del derecho (X); b) de a qué tiene derecho, es decir, cual es el contenido del derecho (Y); y, c) de la razón por la cual este sujeto tiene tal derecho. Estas explicaciones, nos dicen los defensores de esta tesis, sólo se pueden dar en el caso de los derechos civiles y políticos, pero no en el caso de los derechos sociales ya que no son derechos universales, no es posible establecer la naturaleza de las obligaciones que crean y no tienen su fundamento en valores morales sino en preferencias (Vid. R. Plant, "Needs, Agency and Welfare Rights", en J.D. Moon (ed.), Responsability, Rights and Welfare: A Theory of the Welfare State, Westview Press, Boulder, 1988). Estos argumentos han sido rechazados por dos grupos de autores: por un lado, aquellos que niegan la distinta naturaleza jurídica de los derechos sociales con respecto los civiles o políticos aunque a partir de la calificación entre derechos positivos y negativos establecida por C. Fried (Right and Wrong, Harvard University Press, Cambridge, 1978) sí afirman existir una distinta naturaleza de las medidas que se necesitan para hacer efectivos cada uno de estos grupos de derechos, lo que justificaría un trato desigual entre ellos (Vid. V. Kartashkin, "Economic, Social and Cultural Rights", en K. Vasak y P. Alston (eds.), The Internacional Dimensions of Human Rights, Greenwood Press, París, 1982, Vol. I, p. 112; E. Van de Luytgaarden, Introduction to the theory of Human Rights Law, Universidad de Utrecht, Holanda, 1993); y, por otro lado, aquellos autores que partiendo del principio de indivisibilidad, interdependencia e interrelación de los derechos, señala que cualquier trato diferenciado entre grupos de derechos no está justificado y tiene que ver más con diferencias ideológicas 
a la educación del art. 27 CE) dentro del capítulo "Principios rectores de la política social y económica" (arts. 39 al 52). Asimismo tampoco les otorga aplicabilidad directa, sino que de acuerdo con el art. 53.3 CE son principios de libre configuración legislativa, quedando su justiciabilidad condicionada a su desarrollo legislativo. ${ }^{28}$

Ello hace que las disposiciones referidas a los derechos sociales que la Constitución contiene, en tanto principios de políticas públicas de libre configuración legislativa, son mandatos normativos dirigidos al legislador, por tanto, solo afectará a los demás órganos del Estado y a los particulares en la medida en que sus preceptos hayan sido desarrollado mediante una ley. ${ }^{29}$ Prueba de ello es que en aquellas ocasiones en que en aplicación del Estado constitucional se procede a la justiciabilidad directa de derechos sociales, que efectivamente también las hay, se hace indirectamente por la vía de relacionarlos o considerarlos parte de otros derechos fundamentales pero no mediante su aplicación directa dada la dificultad de derivar ex constitutione una justiciabilitat absoluta e incondicional de todo el contenido de estos derechos. ${ }^{30}$ Valga como ejemplo, la protección en repetidas ocasiones del derecho a la salud del art. 43 CE por la vía de vincularlo o considerarlo parte del derecho a la vida y la integridad física del art. $15 \mathrm{CE} .^{31}$

En consecuencia, la eficacia indirecta de partes importantes de la Constitución que afectan a materias en relación a las cuales se dan a menudo episodios de movilización y resistencia popular (como son los derechos sociales) implica que la Constitución, como fuente jurídica suprema, sólo obliga en éstas directamente al legislador que se verá obligado a acomodar el contenido de sus leyes a la Constitución, siendo éstas objeto de control de constitucionalidad, de tal suerte que la Constitución solo estará presente en la vida jurídica por mediación del legislador y del órgano que lleve a cabo el control de constitucionalidad, ${ }^{32}$ pero no en la relación de los ciudadanos con la justicia ordinaria que continuará estando mediada por la

que con diferencias conceptuales o teóricas de los derechos entre ellos o medidas de implementación de los mismos (Vid. P. Hunt, Reclaiming Social Rights. International and Comparatives Perspectives, Dartmouth, Great Britain, 1996, pp.7 y ss.; A. Noguera, "Derechos fundamentales, fundamentalísimos o, simplemente, derechos? el principio de indivisibilidad de los derechos en el viejo y el nuevo constitucionalismo", Derechos y libertades, No. 21, 2009, pp. 117-147).

${ }^{28}$ La STC 80/1982, de 20 de diciembre, señaló que "el valor normativo inmediato de los artículos 39 a 52 de la Constitución ha de ser modulado en los términos del artículo 53.3 de la Norma Fundamental” (FJ1). El art. 53.3 CE establece: “(...) los principios reconocidos en el Capítulo tercero (...) Sólo podrán ser alegados ante la Jurisdicción ordinaria de acuerdo con lo que dispongan las leyes que los desarrollen”.

${ }^{29}$ Así lo considera el propio Tribunal Constitucional (TC). De un lado, a partir de identificar la inviable tutela directa a través del recurso de amparo con la imposibilidad de perfilar posiciones subjetivas a partir de los principios rectores, el TC da a entender que de los principios rectores no cabe obtener ningún tipo de derecho subjetivo (ATC 241/1985). De otro lado, subraya el carácter no vinculante de los medios necesarios para cumplir los fines o las prestaciones constitucionales; por ejemplo, en relación al principio de protección familiar (art. 39) sostiene que "es claro que corresponde a la libertad de configuración del legislador articular los instrumentos normativos o de otro tipo, a través de los que hacer efectivo el mandato constitucional, sin que ninguno de ellos resulte a priori constitucionalmente obligado" (STC 222/1992); y, lo mismo cabe decir de la seguridad social, pues si bien corresponde a todos los poderes públicos la tarea de acercar la realidad al horizonte de los principios rectores, de "entre tales poderes son el legislador y el gobierno quienes deben adoptar decisiones y normas...” (STC 189/1987).

30 Sobre ello, ver: A. NOGUERA, "El Estado social y el tratamiento de los derechos sociales en la Constitución Española de 1978”, en A. NOGUERA y A. GUAMÁN (dir.), Lecciones sobre Estado social y derechos sociales, Tirant lo Blanch, Valencia, 2014, pp. 197-210.

${ }^{31}$ Ver como ejemplos las SSTC 119/2001, 5/2002, 62/2007, 160/2007 o 37/2011.

32 J. MONTAÑA, Teoría utópica de las fuentes del derecho ecuatoriano, Corte Constitucional/CEDEC, Quito, 2012, p. 26. 
ley ordinaria. De acuerdo con el citado art. 53.3 CE un ciudadano no puede exigir directamente por vía judicial un derecho social, aunque aparezca en la Constitución, si no existe una ley ordinaria que lo desarrolle.

A diferencia de ello, la gran novedad de las nuevas constituciones latinoamericanas es que sí rompen totalmente con la supremacía de la ley e imponen de manera clara la supremacía de la Constitución en todos sus elementos, también en el marco de las relaciones entre ciudadanos y justicia ordinaria. Como lo hacen?

Por un lado, reconocen el principio de aplicabilidad directa e inmediata por y ante cualquier funcionario público, administrativo o judicial, de oficio o a petición de parte, de todos los derechos y principios constitucionales de justicia. Así como la imposibilidad de ninguna norma jurídica de poder restringir el contenido de los derechos (art. 22 Constitución venezolana).

Por otro lado, hacen un desarrollo largo y casi reglamentario de los derechos. Ello evita la indeterminación y permite una completud que hace de estas constituciones un instrumento didáctico y normativo mediante el cual se pueden resolver casi todos los asuntos.

Todo ello permite que estas constituciones puedan conformarse en fuente directa de posiciones subjetivas para los jueces en todo tipo de relaciones.

En consecuencia, la relación entre ciudadano y justicia ordinaria ya no está mediada principalmente por la ley sino directamente por la Constitución. Fruto de este cambio en la cultura jurídica de las fuentes del derecho el rol del juez cambia total y radicalmente, pasando a ser un activo realizador o implementador directo de los derechos y del interés general en los juicios. Los jueces abandonan el fantasma del formalismo positivista, adoptando la responsabilidad moral y política de tener que intervenir para hacer efectivos directamente los derechos y los principios constitucionales de justicia.

\section{A) EL MODELO PROCESAL EN LA CONSTITUCIÓN BOLIVARIANA DE 1999}

Las anteriores características hacen que el primer modelo procesal civil tipo descrito, el modelo de la justicia de procedimiento, sea abiertamente incompatible con el nuevo constitucionalismo latinoamericano. Pero además, ello también se desprende directamente de determinados artículos de la Constitución bolivariana de 1999 que apuesta claramente por el modelo de la justicia de la decisión.

$\mathrm{El}$ art. 297, refiriéndose al proceso judicial, dice textualmente: "El proceso constituye un instrumento fundamental para la realización de la justicia”. Ello genera como consecuencia la obligación de estructurar el proceso civil de acuerdo con el segundo de los modelos descritos, donde se otorgue un papel activo y preponderante de los jueces sobre el de las partes o sus abogados. Las propias características de los jueces hacen que estos se encuentren en mejores condiciones de hacer efectivos los derechos y principios constitucionales de justicia que las partes y sus abogados. ${ }^{33}$ Entre otras cosas porqué la función de los abogados es persuadir al juez desde una posición de parte y mediante recursos oratorios para que dé la razón

\footnotetext{
${ }^{33}$ La llamada "Rights-based justification" defiende que en toda sociedad justa hay unos derechos fundamentales que tienen que garantizarse a todos los individuos, independientemente de si la mayoría quiera o no. A la vista de esta consideración, nos dicen que hay que reconocer que existen determinadas características institucionales de los tribunales (el tiempo, la experiencia, la responsabilidad y justificación, etc.) que los hacen más susceptibles de proporcionar una protección más adecuada a los derechos que las instituciones representativas, entre ellas el legislativo, u otros actores. Por tanto, parece lógico que pueda existir una posibilidad de los tribunales de revisar el cumplimiento o no de los derechos fundamentales por parte de los 
a su cliente que es quien le paga para ello, independientemente de si ello favorece o no a los principios constitucionales políticamente consensuados por el constituyente. En cambio, la función del juez es ubicarse por encima de las partes e intentar resolver el caso aplicando los derechos y principios de justicia constitucional que estableció el constituyente.

Además, lo anterior queda confirmado cunado el propio art. 257 de la Constitución, después de decir que el proceso constituyente es un instrumento para la realización de la justicia, señala que "las leyes procesales establecerán la simplificación, uniformidad y eficacia de los trámites y adoptarán un procedimiento breve, oral y público", elementos que, en gran parte, deben entenderse unidos al principio de inmediación del juez, lo que confirma la opción de la Constitución por el segundo de los modelos planteados.

\section{B) EL PROYECTO DE REFORMA DEL CÓDIGO DE PROCEDIMIENTO CIVIL}

En resumen, parece del todo claro que de los dos modelos procesales tipo que hemos planteado, el segundo es el que encaja con el nuevo constitucionalismo latinoamericano, y de hecho una mirada al proyecto de Código de Procedimiento Civil que a iniciativa del Tribunal Supremo de Justicia de Venezuela se presentó a la Asamblea Nacional en 2014, permite ver que la reforma va en el sentido de acentuar y profundizar este segundo modelo procesal civil que hemos descrito. Para poner sólo algunos ejemplos de las disposiciones que el Proyecto de Reforma del Código de procedimiento Civil introduce podemos referirnos a:

El art. 4 referido a la finalidad del proceso señala que "el proceso es un instrumento para la realización de la Justicia, de conformidad con lo previsto en el art. 257 de la Constitución. A esta finalidad deberá atenerse el juez al adoptar su decisión”. El art. 6 que recoge los "Principios del Proceso" incorpora en uno de sus subapartados, el de la "instrumentalidad del proceso", señalando "las disposiciones contenidas en el presente código sirven a la realización de la Justicia como valor superior del Estado y como instrumento de equilibrio social". Además, la ruptura con el formalismo jurídico y el imperio de la ley, estableciendo la posibilidad de los jueces de adoptar un rol activo aplicando directamente la ley, se plasma en el art. 16 que establece el "control difuso de constitucionalidad de la ley", diciendo: "cuando el juez considere que hay contradicción entre la ley u otra norma jurídica y algún valor, principio o norma constitucional, se aplicarán las disposiciones constitucionales, correspondiendo al juez decidir de oficio o a petición de parte lo conducente". También el hecho de que sea un proceso basado en la concentración de actos, la oralidad y la inmediación, favorece el segundo modelo.

\section{LA DEMOCRATIZACIÓN DE LA JUSTICIA Y EL PROCESO: UNA JUSTICIA ADAPTADA AL NUEVO CONSTITUCIONALISMO}

Vista la cuestión referida a la relación entre técnica judicial y normas jurídicas o el rol de los jueces en el proceso, veremos a continuación el otro aspecto al que nos referíamos al inicio.

Dotar de más poder a los jueces debe ir acompañado necesariamente de mayor control y exigencia de responsabilidad sobre ellos, lo que exige una democratización de la justicia. Partiendo de las tesis de la llamada objeción contramayoritaria representada, entre otros, por

representantes políticos (Sobre ello, vid. D. Bilchtz, Poverty and Fundamental Rights, Oxford University Press, Oxford, 2007, pp. 120-128). 
Jeremy Waldron, ${ }^{34}$ podríamos decir que el hecho de que establezcamos un modelo donde las decisiones de los jueces, quienes no tienen legitimidad democrática directa pues no han sido elegidos por los ciudadanos, no sean sólo interpretativas sino que tengan un carácter claramente político de realización de la Constitución, pudiendo incluso, mediante el control difuso de constitucionalidad, inaplicar alguna ley aprobada por los representantes democráticamente electos, podría llegar a implicar ciertas contradicciones con el principio democrático. ${ }^{35}$ ¿Están los jueces legitimados pues no han sido electos democráticamente para inaplicar leyes dictadas por representantes que sí lo han sido o para tomar decisiones de contenido político? ¿Supone esto un choque con el principio democrático? $\mathrm{Si}$ bien este argumento ha sido, tradicionalmente, desmontado por autores como Carlos Santiago Nino, ${ }^{36}$ entre otros, argumentando que los beneficios morales de la institución judicial, como es la protección de los derechos fundamentales y principios constitucionales, superan los costes de tener que aceptar, por ejemplo, el hecho de que personas no electas puedan inaplicar leyes de los representantes electos; no cabe duda de que en modelos donde los jueces tienen control difuso de constitucionalidad y un amplio margen de maniobra a la hora de tomar sus decisiones, tal contradicción democrática existe y, por tanto, hay que buscar mecanismos de democratización del Poder judicial que permitan apaciguarla. Además, así lo exige también la propia Constitución venezolana, estableciendo como principio fundamental la democracia participativa y protagónica del pueblo en los diferentes ámbitos de la sociedad. Con respecto al ámbito judicial, la Constitución en-

\footnotetext{
${ }^{34}$ Waldron desarrolla sus principales argumentos cuestionando el control judicial de constitucionalidad como un mecanismo de decisión apropiado para una sociedad democrática, en su obra Law and desagreement [Clarendon Press, Oxford, 1999 (Trad. al español: J.L. Martí y A. Quiroga, Marcial Pons, Madrid, 2006)] y en un artículo publicado en la revista de derecho de la Universidad de Yale: "The Core of the Case Against Judicial Review" [Yale Law Journal, Núm. 115 (6), pp. 1346-1406].

${ }^{35}$ Waldron parte de la idea de que existe un compromiso de la mayor parte de los ciudadanos y funcionarios públicos con la idea de los derechos individuales. Todos reconocen que a toda persona deben respetársele ciertos derechos y libertades. Ahora bien, existe, a la vez, un desacuerdo "persistente, sustancia, y de buena fe" entre los miembros de la sociedad sobre el contenido, los límites y el alcance de los derechos. Algunos de estos desacuerdos se dan en el nivel filosófico (por ejemplo, ¿̇han de incluirse dentro de la Carta de derechos los Derechos Económicos, Sociales y Culturales?), otros en el plano interpretativo frente a circunstancias concretas (¿autoriza el derecho al pluralismo político que partidos xenófobos puedan presentarse a las elecciones?). Waldron asume que estos desacuerdos entre derechos, son conflictos que necesitan una respuesta, necesitan fijar un curso de acción para la sociedad, pero no son exclusivamente materia de interpretación en un sentido puramente jurídico o formalista, sino que al definir elecciones cruciales de cualquier sociedad, deben enfrentarse en el contexto del debate moral y político existente, tales como si resulta moralmente correcto autorizar la pena de muerte, el derecho al aborto, la eutanasia, los matrimonios homosexuales o permitir la financiación privada sin límites de las campañas electorales (S. Linares, La (i)legitimidad democrática del control judicial de las leyes, Marcial Pons, Madrid-Barcelona-Buenos Aires, 2008, pp. 68-69). Ello hace que, a diferencia de Dworkin que dice que los jueces son los que están mejor posicionados para tomar este tipo de decisiones (R. Dworkin, Freedom's Law. The Moral Reading of the American Constitution, Harvard University Press, Cambridge, 1996), para Waldron no sea así, estos son unos debates que se tiene que dar, no en los órganos jurisidiccionales puesto que los jueces -dice- se mueven por intereses egoístas, sino en el espacio (sociedad) y órganos políticos, concretamente, el legislativo. Esto permite: a) enfrentar el debate en el contexto socio-político (el debate en la cámara debe ir precedido de una amplia y participativa discusión pública en el seno de la sociedad, lo que garantiza el derecho de participación ciudadana, aspecto fundamental para Waldron); y, b) establecer, a través de la decisión parlamentaria, la acción colectiva sin necesidad de que los ciudadanos se pongan de acuerdo, allí donde una respuesta es necesaria y el acuerdo imposible.

${ }^{36}$ C.S. NINO, "La filosofía del control judicial de constitucionalidad", Revista del Centro de Estudios Constitucionales, No. 4, 1989, pp. 79-88.
} 
tiende esta democratización tanto desde una perspectiva cualitativa como cuantitativa.

La democratización desde una perspectiva cualitativa se refiere al establecimiento y mejora de mecanismos de corresponsabilidad ciudadanos-Estado en el acto de administración de justicia, así se desprende del art. 23 de la Constitución que establece que la potestad de administrar justicia emana de los ciudadanos.

Mientras que la democratización desde una perspectiva cuantitativa se refiere a la necesidad de universalizar y no excluir a nadie del acceso a la justicia, así se deriva del art. 26 de la Constitución que señala que toda persona tiene derecho al acceso a una justicia gratuita, accesible y sin formalismos.

$\mathrm{Y}$, ¿Cuáles son las vías para proceder a democratizar la justicia desde estas dos perspectivas? ¿Puede hacer algo el Código de Procedimiento Civil en este sentido?

\subsection{DEMOCRATIZACIÓN DE LA JUSTICIA DESDE UN PUNTO DE VISTA CUALITATIVO}

Democratizar la justicia desde esta perspectiva implica introducir transformaciones en dos ámbitos de ésta, a las que, a partir de una vieja clasificación de Lawrence Friedman, ${ }^{37}$ llamaremos: la cultura legal externa y la cultura legal interna.

Por un lado, la cultura legal externa se refiere al conjunto de maneras de actuar que la población en general, los ciudadanos, tienen con respecto y hacia las instituciones judiciales.

Transformaciones democratizadores en este ámbito serían por ejemplo, el desarrollo del art. 255 de la Constitución que establece la garantía de participación ciudadana en el procedimiento de selección y designación de los jueces. O la posibilidad, aunque ello no es posible ni por la Constitución ni por la Ley Orgánica del Consejo de Judicatura, que éste estuviera integrado por miembros de la sociedad civil organizada, pues el órgano de gobierno del poder judicial no necesariamente debería estar compuesto íntegramente por jueces o abogados. Aunque también es cierto que nada de esto depende del Código de Procedimiento Civil.

Por otro lado, la cultura legal interna se refiere al conjunto de maneras de organización interna del proceso, o maneras de actuar especializadas que tienen las cortes o tribunales en su interior. Y aquí sí hay transformaciones democratizadoras que pueden llevarse a cabo desde el derecho procesal civil.

Por ejemplo, si volvemos al Proyecto de Código de Procedimiento Civil presentado a la Asamblea, vemos que en su art. 6 referido a los principios del proceso, cita como alguno de ellos la participación protagónica del pueblo en la administración de justicia, para a continuación, hacer referencia a los medios alternativos de resolución de conflictos tales como la mediación o la conciliación, entre otros. El proyecto establece que a lo largo de todo el proceso el juez debe promover la posibilidad de utilización de los medios alternativos de resolución de conflictos. ¿Qué implican estos principios?

Tradicionalmente, los mecanismos de resolución alternativa de conflictos se han asociado a un determinado tipo de mediación o conciliación que es la mediación intrajudicial o conectada al tribunal, que se lleva a cabo una vez iniciado el proceso y que es realizada por el propio juez u otro operador jurídico, normalmente el secretario judicial, para quien en muchas ocasiones la mediación, dadas las limitaciones por las circunstancias y el tiempo en

\footnotetext{
${ }^{37}$ L. FRIEDMAN, The Legal System. A Social Science Perspective, Russell Sage Foundation, New Cork, 1975, p. 194.
} 
que éste se encuentra, no es más que un simple trámite en el que sólo pregunta a las partes si quieren llegar a acuerdo.

Sin embargo, ello no tiene que ser así necesariamente. Existen múltiples técnicas alternativas extrajudiciales o no vinculadas estrictamente al tribunal de resolución de conflictos en el ámbito privado: los arbitrajes, el mini-juicio, el proceso "med-arb” (hibridación entre mediación y arbitraje), etc.; que pueden llevarse a cabo en el marco de la justicia comunal de paz venezolana con la participación ciudadana mediante tribunales comunales de paz o Juntas vecinales conciliadoras y de seguimiento, las cuales, en la actualidad, ya resuelven algunos casos en el ámbito del derecho civil como divorcios colaborativos, etc.

Estas asambleas o formas comunales de justicia fueron debatidas en la Asamblea Constituyente venezolana de 1999 y finalmente, se consideró que quedaban integradas dentro de la forma "asambleas ciudadanas con decisiones vinculantes" del art. $70^{38} \mathrm{y}$ en los arts. 178.7,39 $253^{40}$ y $258^{41}$ que se refieren a la justicia de paz como manifestación de democracia directa. La incorporación de estas formas participativas alternativas de resolución conflictos, ya sea de manera previa o durante el proceso, constituye un elemento fundamental de integración de la comunidad en el proceso judicial y de profundización de la corresponsabilidad ciudadanos-Estado en el acto de administrar justicia desde un punto de vista cualitativo de la cultura legal interna. Se trata de experiencias que existen en otros países como Colombia mediante las denominadas "Casas de Justicia".42

Quizá, una pequeña crítica al Proyecto de Reforma del Código de Procedimiento Civil es que más allá de nombrar, en su art. 6, la participación ciudadana y los medios alternativos de resolución de conflictos, no se refiere en ninguna otra parte del texto a ello. Aunque de la lectura literal de los arts. 257 a 261 del Proyecto, referidos a la conciliación no parece quedar

\footnotetext{
${ }^{38}$ Art. 7o Constitución Venezuela: "Son medios de participación y protagonismo del pueblo en ejercicio de su soberanía, en lo político: la elección de cargos públicos, el referendo, la consulta popular, la revocación del mandato, las iniciativas legislativa, constitucional y constituyente, el cabildo abierto y la asamblea de ciudadanos y ciudadanas cuyas decisiones serán de carácter vinculante, entre otros; y en lo social y económico: las instancias de atención ciudadana, la autogestión, la cogestión, las cooperativas en todas sus formas incluyendo las de carácter financiero, las cajas de ahorro, la empresa comunitaria y demás formas asociativas guiadas por los valores de la mutua cooperación y la solidaridad".

39 Art. 178.7 Constitución Venezuela: "Son de la competencia del Municipio el gobierno y administración de sus intereses y la gestión de las materias que le asignen esta Constitución y las leyes nacionales, en cuanto concierne a la vida local, en especial la ordenación y promoción del desarrollo económico y social, la dotación y prestación de los servicios públicos domiciliarios, la aplicación de la política referente a la materia inquilinaria con criterios de equidad, justicia y contenido de interés social, de conformidad con la delegación prevista en la ley que rige la materia, la promoción de la participación, y el mejoramiento, en general, de las condiciones de vida de la comunidad, en las siguientes áreas: (...) 7. Justicia de paz, prevención y protección vecinal y servicios de policía municipal, conforme a la legislación nacional aplicable”.

${ }^{40}$ Art. 253 Constitución Venezuela: "La potestad de administrar justicia emana de los ciudadanos y ciudadanas y se imparte en nombre de la República por autoridad de la ley. (...)El sistema de justicia está constituido por el Tribunal Supremo de Justicia, los demás tribunales que determine la ley, el Ministerio Público, la Defensoría Pública, los órganos de investigación penal, los o las auxiliares y funcionarios o funcionarias de justicia, el sistema penitenciario, los medios alternativos de justicia, los ciudadanos o ciudadanas que participan en la administración de justicia conforme a la ley y los abogados autorizados o abogadas autorizadas para el ejercicio".

${ }^{41}$ Art. 258 Constitución Venezuela: "La ley organizará la justicia de paz en las comunidades. Los jueces o juezas de paz serán elegidos o elegidas por votación universal, directa y secreta, conforme a la ley. La ley promoverá el arbitraje, la conciliación, la mediación y cualesquiera otros medios alternativos para la solución de conflictos".

$4^{2}$ http://www.casasdejusticia.gov.co/SitePages/inicio.aspx

CienCIA JURÍDICA. Departamento de Derecho. División de Derecho, Política y Gobierno, Universidad de Guanajuato - Año 4, No. 8, 2015
} 
cerrada la posibilidad de que puedan darse formas extrajudiciales alternativas de resolución de conflictos llevadas a cabo por los órganos de justicia comunal, tampoco se hace en ningún momento mención expresa a ello.

Posiblemente hubiera sido oportuno explicitar textualmente la articulación entre tribunales y justicia comunal con participación ciudadana para determinadas materias y cuantías, pudiendo incluso establecer esta última como forma de conciliación de carácter obligatorio previa al proceso en tales materias y cuantías, y con carácter voluntario durante el proceso. ${ }^{43}$

Aunque el texto del proyecto no lo descarte y se pueda sobreentender, incluirlo expresamente, si bien no es estrictamente necesario e incluso puede ser no recomendable desde la puridad de la técnica legislativa, sí que puede ayudar a que tal aspecto sea objeto de mayor atención política y pública.

Este es, en consecuencia, uno de los aspectos mediante el cual el Derecho procesal civil puede ayudar a una democratización de la justicia desde una perspectiva cualitativa.

\subsection{DEMOCRATIZACIÓN DE LA JUSTICIA DESDE UN PUNTO DE VISTA CUANTITATIVO}

¿Qué aportes pueden hacerse desde el derecho procesal civil para la universalización de la justicia? Aquí podemos hacer referencia a diversas cuestiones.

Una es la adecuación del Derecho procesal civil a las nuevas dimensiones colectivas en el Derecho, lo que ocurre a través de la construcción de sujetos colectivos de derecho. A ello me refería al inicio cuando hablaba de la necesidad de adaptar el Código "por arriba" pero también "por abajo" donde, entre otros, se produce un fenómeno de sustitución de la concepción civilista clásica de las relaciones sociales basada en la idea del "hombre contra hombre" por la del "hombre más hombre", implicando cambios en los sujetos litigantes de referencia.

En el caso venezolano, esta posibilidad ya se da en Código procesal civil vigente. El art. 138 se refiere a personas jurídicas y el art. 139 a "sociedades irregulares, asociaciones y comités que no tienen personalidad jurídica", ${ }^{4}$ artículos que se reproducen en el nuevo proyecto de Código.

Otra de las cuestiones a las que se puede hacer referencia es el acceso a la justicia. Éste no sólo depende de la situación jurídica en que se encuentran las personas, la defensa judicial de los intereses de un sujeto o grupo implica tener que movilizar un conjunto de recursos económicos, intelectuales, socio-culturales, de información y conocimiento, facilidad lingüística y de comprensión, etc. de los que muchas veces no disponen aquellos grupos socia-

\footnotetext{
${ }^{43}$ Una de las novedades que en este sentido presenta el nuevo Código Procesal Civil boliviano es que si hasta ahora la conciliación era un acto potestativo de las partes y del juez, ahora, con el nuevo Código, para iniciar el proceso y antes de la demanda, obligatoriamente se deberá agotar la conciliación (Vid. art. 292 Código Procesal Civil Bolivia: "Se establece con carácter obligatorio la conciliación previa, la que se regirá por las disposiciones del presente Código, por lo que al promoverse demanda principal deberá acompañarse acta expedida y firmada por el conciliador autorizado").

44 Art. 139: "Las sociedades irregulares, las asociaciones y los comités que no tienen personalidad jurídica, estarán en juicio por medio de las personas que actúan por ellas o a las cuales los asociados o componentes han conferido la representación o la dirección. En todo caso, aquellos que han obrado en nombre y por cuenta de la sociedad, asociación o comité, son personal y solidariamente responsables de los actos realizados".
} 
les en situación de vulnerabilidad. ${ }^{45}$ ¿Qué mecanismos pueden reconocerse para facilitar el acceso a la justicia de estos grupos?

Un documento de referencia es las Reglas de Brasilia aprobadas en la XIV Cumbre Judicial Iberoamericana, del 4 al 6 de marzo de $2008,{ }^{46}$ que establecen unos estándares básicos para garantizar el acceso a la justicia de las personas en condiciones de vulnerabilidad por razón de género, étnica, económicas o sociales, etc.

Una mirada al proyecto de reforma del Código Procesal Civil venezolano permite ver que este incorpora los principales estándares de reglas de procedimiento, así como de organización y gestión judicial, destinadas a facilitar el acceso universal a la justicia tales como: promoción de una asistencia legal y defensa pública de calidad y especializada, asistencia jurídica gratuita cuando sea necesario, revisión de las reglas de procedimiento priorizando la oralidad, concentración de actos, celeridad, etc.

Sin embargo, es cierto también que quedan varios aspectos que podrían añadirse y que contribuirían todavía más a garantizar este mayor acceso a la justicia. Entre ellos podemos hacer referencia a los siguientes:

Mientras el art. 68 del nuevo Código Procesal Civil boliviano de 2013 reconoce la posibilidad en los actos procesales de utilizar cualquier idioma de los reconocidos en el país, ${ }^{47}$ el art. 168 del proyecto venezolano establece que sólo podrá usarse el castellano. Este es un aspecto a mejorar que incluso podría entrar en conflicto con el art. 9 de la Constitución y el derecho internacional indígena, concretamente, el Convenio 169 de la OIT sobre pueblos indígenas y tribales (1989) y la Declaración de las Naciones Unidas sobre los derechos de los pueblos indígenas (2007).

Otro aspecto es el de la legitimación para presentar demandas. Tanto el nuevo Código boliviano como el proyecto venezolano requieren siempre de abogado y procurador para presentar demanda. Existen países donde se reconocen supuestos donde los ciudadanos pueden acceder directamente a la justicia, en el ámbito civil, sin necesidad de abogado o procurador. En Estados Unidos, los ciudadanos pueden acudir a las Cortes de pequeños reclamos sin necesidad de abogado. $\mathrm{O}$ en España la LEC tampoco requiere obligatoriedad de abogado o procurador para determinados supuestos..$^{48}$ En estos casos, para facilitar el acceso y la redacción de demandas sin abogado, los juzgados tienen que facilitar impresos y formularios muy simples que el demandante debe rellenar.

Vinculado a ello, otras medidas para facilitar el acceso a la justicia de los más vulnerables serían, por ejemplo: el art. 69.1 del nuevo Código boliviano establece explícitamente que los memoriales de las partes pueden ser redactados por medio técnico o "a mano con letra legible". O respecto a la petición de asistencia jurídica gratuita, el nuevo Código boliviano establece que la petición de gratuidad podrá hacerse de forma previa al proceso y sin firma

\footnotetext{
${ }^{45}$ M. Daly, Acces to social rights in Europe, Consejo de la Unión Europea, Estrasburgo, 2002, pp. 31-32.

${ }^{46} \mathrm{http} / / /$ www.poderjudicial.gob.hn/CUMBREJUDICIALIBEROAMERICANA/Documents/10oREGLASDE BRASILIASOBREACCESOALAJUSTICIAPERSONASV.pdf

47 Art. 68.I CPC Bolivia: "En los actos procesales se utilizará el idioma castellano o el preponderante en la región, que será definido por la Sala Plena de cada Tribunal Departamental de Justicia, asegurando que en los tribunales de apelación y casación sean perfectamente entendibles los actuado".

${ }^{48}$ Art. 23.2 LEC: “(...) podrán los litigantes comparecer por sí mismos: $1^{\circ}$. En los juicios verbales cuya cuantía no exceda de 2.000 euros y para la petición inicial de los procedimientos monitorios, conforme a lo previsto en esta Ley $22 ; 2 .^{\circ}$ En los juicios universales, cuando se limite la comparecencia a la presentación de títulos de crédito o derechos, o para concurrir a Juntas; $3 .^{\circ}$ En los incidentes relativos a impugnación de resoluciones en materia de asistencia jurídica gratuita y cuando se soliciten medidas urgentes con anterioridad al juicio". 
de abogado, lo que facilita mayor acceso a la justicia que el nuevo proyecto venezolano, el cual en su art. 178, manteniendo el vigente art. 176 aunque con redactado distinto, señala que la petición de gratuidad podrá hacerse por escrito motivado junto a la interposición de la demanda, de la contestación o en cualquier otro momento del proceso. El hecho de que una persona sin recursos deba acudir a un abogado e iniciar el proceso para pedir la gratuidad actúa como elemento disuasorio, siendo mucho más fácil que pudiera hacerlo de manera previa y por su cuenta.

Todos estos son algunos aspectos que podrían revisarse en la tramitación del proyecto en la Asamblea Nacional durante el proceso de aprobación en lo particular.

\section{CONCLUSIÓN}

Tal como hemos afirmado, la adecuación del derecho Procesal Civil "por arriba” y "por abajo" al neoconstitucionalismo latinoamericano y su nueva realidad exige básicamente:

Primero, una modificación en el rol de los jueces durante el proceso y en su relación con las partes. Concretamente se requiere una intervención activa, directa y enérgica de los jueces mediante la aplicabilidad directa de la Constitución para la tutela del interés general y social, así como una mayor celeridad procesal mediante la eliminación o reducción temporal de trámites no esenciales y de la articulación del proceso alrededor de los principios de inmediación del juez, de oralidad, o de concentración de los catos procesales en la audiencia.

Y segundo, profundizar en el proceso de democratización y participación popular en el ámbito de la justicia. Dotar de más poder a los jueces debe ir acompañado necesariamente de mayor control y exigencia de responsabilidad sobre ellos, lo que exige una democratización de la justicia. Con respecto al ámbito judicial, la Constitución entiende esta democratización tanto desde una perspectiva cualitativa refiriéndose al establecimiento y mejora de mecanismos de corresponsabilidad ciudadanos-Estado en el acto de administración de justicia (art. 23); y cuantitativa, en referencia a la necesidad de universalizar y no excluir a nadie del acceso a la justicia (art. 26).

Las dos exigencias son incorporadas a través de los elementos anteriormente descritos en el Proyecto de Código Procesal Civil venezolano elaborado a iniciativa del TSJ, presentado el 2014 en la Asamblea Nacional y que todo indica que se aprobará antes de acabar el año 2015.

Con ello se contribuye a la consolidación del modelo constitucional propio y diferenciado inaugurado por las recientes constituciones latinoamericanas.

\section{FUENTES}

BIBLIOGRÁFICAS

ABRAMOVICH, V. y COURTIS, C. (2002), Los derechos sociales como derechos exigibles, Trotta, Madrid.

ACANDA, J.L. (2002), Sociedad civil y hegemonía, Centro Juan Marinello, La Habana.

ASENCIO, J.M. (2004), Introducción al Derecho Procesal, Triant lo Blanch, Valencia.

BILCHTZ, D. (2007), Poverty and Fundamental Rights, Oxford University Press, Oxford. 
CABEZUDO, N. (2010), Del principio de inmediación, sus excepciones y los instrumentos electrónicos, Tirant lo Blanch, València.

CORREAS, O. (1994), Kelsen y los marxistas, Coyoacán, México.

DAU-LIN, H. (1998), Mutación de la Constitución, IVAP, Bilbao.

DALY, M. (2002), Acces to social rights in Europe, Consejo de la Unión Europea, Estrasburgo.

DWORKIN, R. (1996), Freedom's Law: The Moral Reading of the American Constitution, Oxford UP, Oxford.

FERRAJOLI, L. (1995), Derecho y razón. Teoría del garantismo penal, Trotta, Madrid.

FRIED, C. (1978), Right and Wrong, Harvard University Press, Cambridge.

FRIEDMAN, L. (1975), The Legal System. A Social Science Perspective, Russell Sage Foundation, New Cork.

GIMENO Sendra, V. (2003), Introducción al Derecho Procesal, Madrid.

HÄBERLE, P. (1998), Libertad, igualdad, fraternidad. 1789 como historia, actualidad y futuro del Estado Constitucional, Trotta, Madrid.

HEGEL, G.W.F. (1987), Principios de la filosofía del derecho, Edhasa, Barcelona.

HUNT, P. (1996), Reclaiming Social Rights. International and Comparatives Perspectives, Dartmouth, Great Britain.

JELLINEK, G. (1991), Reforma y mutación de la Constitución, Centro de Estudios Constitucionales, Madrid.

KANT, E. (1956), Metafísica dei costumi, Utet, Torino.

KARTASHKIN, V. (1982), "Economic, Social and Cultural Rights”, en K. Vasak y P. Alston (eds.), The Internacional Dimensions of Human Rights, Greenwood Press, París, Vol. I.

LABAND, M. (1907), “Die geschichtliche Entwicklung der Reichsverfassung”, en Jahrbuch des öffentlichen Rechts (JöR), Tomo I.

LINARES, S. (2008), La (i)legitimidad democrática del control judicial de las leyes, Marcial Pons, Madrid-Barcelona-Buenos Aires.

MONTAÑA, J. (2012), Teoría utópica de las fuentes del derecho ecuatoriano, Corte Constitucional/CEDEC, Quito.

MONTERO AROCA J., GÓMEZ COLOMER J.L., MONTON A. y BARONA S. (2007), Derecho Jurisdiccional I (parte general), Tirant lo Blanch, Valencia.

NINO, C.S: (1989), "La filosofía del control judicial de constitucionalidad", Revista del Centro de Estudios Constitucionales, No. 4. (1996), The Constitution of Deliberative Democracy, Yale UP, New Haven-Londres. 
NOGUERA, A. (2009), "Reflexiones a partir del análisis del presidencialismo en la Constitución venezolana: acción de gobierno y articulación Ejecutivo-ciudadanos". En F. PALACIOS y D. VELÁZQUEZ (coord.). Estudios sobre la Constitución de la República Bolivariana de Venezuela. X Aniversario, Procuraduría General de la Republica, Caracas.

(2009), "Derechos fundamentales, fundamentalísimos o, simplemente, derechos? el principio de indivisibilidad de los derechos en el viejo y el nuevo constitucionalismo", Derechos y libertades, No. 21.

(2014), "El Estado social y el tratamiento de los derechos sociales en la Constitución Española de 1978”, en A. NOGUERA y A. GUAMÁN (dir.), Lecciones sobre Estado social y derechos sociales, Tirant lo Blanch, Valencia.

NOGUERA, A. y CRIADO, M. (2011), "La Constitución colombiana de 1991como punto de inicio del nuevo constitucionalismo en América Latina", Estudios Socio-jurídicos, Universidad del Rosario, No. 13(1), Bogotá.

Oliva SANTOS A., DIEZ-PICAZO GIMÉNEZ I. y VEGA J. (2004), Derecho Procesal, Editorial universitaria Ramón Areses, Madrid.

PLANT, R. (1988), "Needs, Agency and Welfare Rights", en J.D. Moon (ed.), Responsability, Rights and Welfare: A Theory of the Welfare State, Westview Press, Boulder.

POZZOLO, S. (1998), "Neoconstitucionalismo y especicidad de la interpretación constitucional. Doxa. Cuadernos de Filosofía del Derecho, 21(2).

PRADA, R. (2011), Horizontes del cambio: Estado Plurinacional y socialismo comunitario, en I. ERREJÓN y A. SERRANO (coord.), Ahora es cuando, carajo! Del asalto a la transformación del Estado en Bolivia, El viejo topo, Madrid.

Tapia, L. (2002), La condición multisocietal; multiculturalidad, pluralismo y modernidad, Muela del diablo/CLACSO, La Paz. (2008). Una reflexión sobre la idea de un Estado plurinacional, Enlace, La Paz.

VAN DE LUYTGAARDEN, E. (1993), Introduction to the theory of Human Rights Law, Universidad de Utrecht, Holanda.

VICIANO, R. y MARTÍNEZ, R. (2011), "Fundamentos teóricos y prácticos del nuevo constitucionalismo latinoamericano", Gaceta Constitucional, No. 48, Tribunal Constitucional, Lima.

(2013), "La Constitución democrática, entre el neoconstitucionalismo y el nuevo constitucionalismo", El Otro derecho, No. 48, Bogotá.

VEGA, P. de (1985), La reforma constitucional y la problemática del Poder Constituyente, Tecnos, Madrid.

VEGA, O. (2010), Errancias. Aperturas para el buen vivir, Muela del Diablo/CLACSO, La Paz. 
(2013), "Estado plurinacional", en Constitución política del Estado. Anotada, concordada y comentada, Centro de Estudios Constitucionales, Universidad Católica Boliviana San Pablo, La Paz.

WALDRON, J. (1999), Law and desagreement, Clarendon Press, Oxford.

(2006), “The Core of the Case Against Judicial Review”, Yale Law Journal, Núm. 115 (6).

ZAGREVELSKY, G. (2011), El derecho dúctil, Trotta, Madrid. 